\title{
Integration of Aquaculture with Rice Farming: A Way to Increase Farm Productivity, Food security, Livelihood Improvement and Better Environment
}

\author{
M. Aminur Rahman
}

\begin{abstract}
For centuries, traditional agricultural systems have contributed to food and livelihood security throughout the world. Recognizing the ecological legacy in the traditional agricultural systems may help us develop novel sustainable agriculture. Rice and fish are the key components of global food security. They are the main carbohydrate and protein sources in the daily diets of around three billion peoples, especially in Asia. Rice-fish culture is an integrated approach to food production and can increase food and income. This system can be practiced with little investment and can maximize the use of existing resources. It is one way to increase the economic benefits from rice fields and at the same time improves livelihood and also develops freshwater fisheries. However, the production of rice and fish do not need to be integrated always by producing the two crops simultaneously, but may be done by alternating production: rice can be grown in the rainy season and fish in the dry season, or the other way round. In areas where rice production is not profitable in all seasons, fish production forms an alternative source of income from the field. Nevertheless, to meet the global demand of food and nutrition for the increasing populations, there is therefore a need to increase rice and fish production simultaneously. Integrated rice-fish farming can play an important role in increasing food production as this system is better than rice monoculture in terms of resource utilization, crop diversity, farm productivity or in economics, and both the quality and quantity of the food products. It has been documented that a mutually beneficial relationship between rice and fish develops in integrated system: Fish reduce rice pests and rice favors fish by moderating the water environment. This positive relationship between rice and fish reduces the need for pesticides in rice fields. Fish also control weeds by feeding on weed roots and offer an extra service by tilling the soil around the rice plants. The fish feces are used as organic manure that provide essential nutrients required to grow healthy rice plants. Furthermore, integrated rice and fish culture optimizes the benefits of scarce land and water resources through complementary use, and exploits the synergies between fish and plant. These findings provide unique insights into how positive interactions and complementary use of resource between species generate emergent ecosystem properties and how modern agricultural systems might be improved by exploiting synergies between species. Integrated aquaculture therefore has ample capacity of making more food available thus enhancing food security. Aside from production enhancement, integrated fish farming also gives a platform for managing environmental integrity through waste recycling and utilization. It is important therefore to encourage farmers and other food production sectors to engage in a production system that will ensure food security in an ecofriendly manner.
\end{abstract}

\footnotetext{
${ }^{* 1}$ Laboratory of Marine Biotechnology, Institute of Bioscience, Universiti Putra Malaysia, 43400 UPM Serdang, Selangor, Malaysia
}

Keywords - Integration, Rice-Fish, Friendly environment, Food security, Production, Benefits.

In the recent years, the global food security is becoming an acute problem because of the increasing world population [1], the limitation of agricultural resources [2], and the effects of global climate change on crop production [3,4]. The world agriculture currently faces great challenges in producing sufficient food while minimizing the negative environmental effects of crop cultivation. In the past 50 years, crop yields have noticeably increased, mainly due to the indiscriminant use of chemical fertilizers and pesticides, the development of new crop varieties, and the improvement in cultivation methods. The extensive application of chemical fertilizers and pesticides for long periods, however, negatively affects the environment, induces pest resistance to pesticides, and increases agricultural costs [5,6]. Because of these, modern agriculture now requires "rethinking" [1, 7], and such rethinking should include reconsideration of traditional agricultural systems [8-10].

In many centuries of the world, traditional agricultural systems have contributed to food and livelihood security [8]. For the reason that traditional agricultural systems have been created, shaped, and maintained by generations of farmers who used management practices that were matched to local conditions, and because these systems are based on diverse species and species interactions, traditional agricultural systems reflect a successful adaptation to different environments and are rich in biological diversity and ecological resilience $[8,11,12]$. The recognition of the ecological heritage of these traditional agricultural systems and the integration of these unique experiences into our future farm designs could help us to develop more sustainable agricultural production. Actually, studies of such traditional systems have already helped scientists create novel farm designs [5, 13-15].

During the recent expansion of modern agriculture based on substantial inputs of fertilizer and pesticides, however, many of these traditional agriculture systems have been disappearing [8]. To preserve these important agriculture systems, the Food and Agriculture Organization, the United Nations Development Program, and the Global Environment Facility developed a program for "globally important agricultural heritage systems (GIAHS)" in 2005 [16]. One of these GIAHS is the rice-fish coculture system that has been 
practiced by farmers in south Zhejiang province, China, for $>1,200$ years (17). In this rice-fish coculture system, the fish is an indigenous, red, soft-scaled common carp (Cypinius carpia) with high genetic diversity [18, 19]. The rice varieties in the system have been changing over time. In the last decade, high-yielding hybrid rice varieties have been dominant [20]. The rice-fish coculture is considered a sustainable form of agriculture because it maximizes the benefits of scarce land and water resources by using relatively few chemical inputs, by producing both carbohydrate and protein products, and by conserving biodiversity [20-24].

Nowadays integrated rice-fish farming is the main source of earning in many parts of the world. It is a technique of fish culture with other organisms i.e. plants or animals to get maximum output through minimum input supply in a minimum time frame. Rice-fish farming systems constitute a unique agro-landscape across the world, especially in tropical and sub-tropical Asia. It is quite old and first started in ancient China about 2000 years ago. It has been estimated around 81 million ha of irrigated rice lands worldwide, with an additional 11 million ha of flood prone land under rice cultivation [25]. Currently the system of rice-fish is being practiced in Bangladesh, Cambodia, Egypt, Indonesia, Republic of Korea, Madagascar, Thailand and Vietnam [25]. In these places, rainfed rice fields are designed to store water for extended periods, creating aquatic ecosystems with many similarities to natural floodplains [26]. These floodplain habitats of rice are later stocked by fish and grown throughout the wet season. However, rice and fish production do not need to be integrated by always producing the two crops simultaneously, but may be done by alternating production: rice can be grown in the rainy season and fish in the dry season, or the other way round. In areas where rice production is not profitable in all seasons, fish production forms an alternative source of income from the field. To meet the increasing global demand for food, there is a need to increase rice and fish production. Integrated rice-fish farming can play an important role in increasing food production as the integrated farming system is better than rice monoculture in terms of resource utilization, diversity, productivity, and both the quality and quantity of the food produced.

The multiple benefits of the integration between rice and fish have been globally documented and could be summarized in enhancing farm productivity either in biomass or in economics. Fish in rice field improves soil fertility through their organic waste. Many reports suggest that integrated ricefish farming is ecologically sound because fish improve soil fertility by generating nitrogen and phosphorus [27, 28]. More importantly, the integrated rice-fish leads to the production of a more balanced diet (rice) as a main source of carbohydrate and fish, which is an important animal protein source required for the health and well-being of rural households. The integration of aquaculture can increase rice yields by 8 to $15 \%$ with an additional average fish production of $260 \mathrm{~kg} / \mathrm{ha}$ [29]. It has also been reported that rice-cum-fish culture becomes able to enhance the net benefit by $64.4 \%$ and yield by $5 \%$ [3032]. Based on field surveys and studies, it has been observed that farmers households usually inclined to eat small fish than sell them in the market and hence, fish consumption contributes significantly in the nutrition of children and lactating mothers to avoid child blindness as well as to reduce infant mortality. By cultivating two products, farmers can decrease the risk of loss if one crop fails. Fish is a source of protein, and by integrating production with rice, farmers can improve their own food security. Fish also consumes the animals which transfer diseases to people, so raising them can improve public health. Some fish species, such as the common carp eat mosquito larvae and snails, which spread disease. Moreover, fish plays a significant role in controlling aquatic weeds, algae and snails, and hence, reduces the need for chemical spray leading to better farm economics within ecologically-sound low-cost, low-risk option for poor rice farmers in Bangladesh and elsewhere. Thus, integration of fish with rice farming improves diversification, intensification and productivity of farms [32, 33, 34]. Because fish feed on insects, pest problems are lower in rice fields that contain fish. The problem, particularly with the "Golden Apple Snail" arose 20 years ago and caused havoc to the rice growth and production, but recently it has been found that common carp is effective in reducing the younger snails by as much as 90 percent. Fish also control weeds by feeding on weed roots and offer an extra service by tilling the soil around the rice plants. The fish's activity in the field helps mix the manure and soil. Fish also excrete manure that is high in nutrients, which the plants use. Furthermore, integrated rice and fish culture optimizes the benefits of scarce land and water resources through complementary use, and exploits the synergies between fish and plant.

However, this beneficial cultivation system was gradually abandoned due to population pressures, decreasing stocks of wild fish and the "Green Revolution" which emphasized highinput monoculture using high-yield rice varieties, pesticides, and herbicides (which are toxic to fish). During the 1980s and early 1990s, rice-fish culture as managed cultivation systems experienced a revival, as concerns over the widespread use of pesticides emerged. Nevertheless, only a small number of farmers are involved in integrated rice-fish farming due to a lack of technical knowledge, and an aversion to the risks associated with flood and drought. Despite these problems, proper policy and planning, positive attitude of administrators and extension workers, free access to information/training facilities for the farmers, required size of quality fingerlings at reasonable prices at the appropriate time, will encourage the farmers and farm entrepreneurs to practice ricecum-fish culture to a greater extent. Therefore, it could be concluded that integrated rice-fish farming can help the global communities keep pace with the current demand for food authenticity through the production of rice and fish in a ecofriendly environment.

\section{REFERENCES}

[1] Godfray, H.C.J., et al. 2010. Food security: The challenge of feeding 9 billion people. Science, 327: 812-818. https://doi.org/10.1126/science.1185383

[2] MacDonald, G.M. 2010. Climate change and water in Southwestern North America special feature: Water, climate change, and sustainability in the southwest. Proceedings of the National Academy of Sciences of the United States of America, 107: 21256-21262. https://doi.org/10.1073/pnas.0909651107

[3] Brown, M.E. and Funk, C.C. 2008. Climate. Food security under climate change. Science, 319: 580-581. 
https://doi.org/10.1126/science. 1154102

[4] Piao, S.L., et al. 2010. The impacts of climate change on water resources and agriculture in China. Nature, 467: 43-51. https://doi.org/10.1038/nature09364

[5] Mäder, P., et al. 2002. Soil fertility and biodiversity in organic farming. Science, 296: 1694-1697. https://doi.org/10.1126/science. 1071148

[6] Tilman. D., Cassman, K.G., Matson, P.A., Naylor. R. and Polasky, S. 2002. Agricultural sustainability and intensive production practices. Nature, 418: 671-677. https://doi.org/10.1038/nature01014

[7] Bromley, D.W. 2010. Food security: Beyond technology. Science, 328: 169. https://doi.org/10.1126/science.328.5975.169-d

[8] Altieri, M.A. 2004. Linking ecologists and traditional farmers in the search for sustainable agriculture. Frontiers in Ecology and the Environment, 2: 35-42. https://doi.org/10.1890/1540-9295(2004)002[0035:LEATFI]2.0.CO;2

[9] Vien, T.D., Leisz, S.J., Lam, N.T. and Rambo AT. 2006. Using traditional swidden agriculture to enhance rural livelihoods in Vietnam's uplands. Mountain Research and Development, 26: 192-196. https://doi.org/10.1659/0276-4741(2006)26[192:UTSATE]2.0.CO;2

[10] Herrero, M., et al. 2010. Smart investments in sustainable food production: Revisiting mixed crop-livestock systems. Science, 327: 822825.

https://doi.org/10.1126/science. 1183725

[11] Zhu. Y.Y., et al. 2000. Genetic diversity and disease control in rice. Nature, 406: 718-722. https://doi.org/10.1038/35021046

[12] Altieri, M.A. and Nicholls, C.I. 2002. The simplification of traditional vineyard based agroforests in northwestern Portugal: Some ecological implications. Agroforestry Systems, 56: 185-191. https://doi.org/10.1023/A:1021366910336

[13] Reganold, J.P., Glover, J.D., Andrews, P.K and Hinman, H.R. 2001. Sustainability of three apple production systems. Nature, 410: 926-930. https://doi.org/10.1038/35073574

[14] Kleijn, D., et al. 2006. Mixed biodiversity benefits of agri-environment schemes in five European countries. Ecology Letters, 9: 243-254, discussion 254-257. https://doi.org/10.1111/j.1461-0248.2005.00869.x

[15] Crowder, D.W., Northfield, T.D., Strand, M.R. and Snyder, W.E. 2010. Organic agriculture promotes evenness and natural pest control. Nature, 466: 109-112. https://doi.org/10.1038/nature09183

[16] Koohanfkan, P. and Furtado, J. 2004. Traditional rice-fish systems as globally indigenous agricultural heritage systems (GIAHS). Proceeding of the FAO Rice Conference. International Rice Commission Newsletter, 53: 66-74.

[17] Wang, Z.B. 1997. Chronicles of Agriculture of Yongjia County (Ocean Press, Beijing), pp. 7-11 (in Chinese).

[18] Wang, C.H. and Li, S.F. 2004. Phylogenetic relationships of ornamental (koi) carp, Oujiang color carp and Long-fin carp revealed by mitochondrial DNA COII gene sequences and RAPD analysis. Aquaculture, 231: 83-91. https://doi.org/10.1016/j.aquaculture.2003.10.040

[19] Wang, C.H., et al. 2006. Genetic parameter estimates for growth-related traits in Oujiang color common carp (Cyprinus carpio var. color). Aquaculture, 259, 103-107. https://doi.org/10.1016/j.aquaculture.2006.05.031

[20] Xie, J., et al. 2011. Conservation of traditional rice varieties in a globally important agricultural heritage system (GIAHS): Rice-fish co-culture. Agricultural Sciences in China 10, 101-105. https://doi.org/10.1016/S1671-2927(11)60059-X

[21] You, X. 2006. Rice-fish culture-a typical model of sustainable traditional agriculture. Agr Archaeological, 4: 222-224 (in Chinese).

[22] Fang, L., Zhang, J.E. and Jiang, Y.P. 2007. The conservation and sustainable development of the rice-fish farming system in Qingtian County, Zhejiang Province as one of globally important ingenious agricultural heritage systems. Chinese Agricultural Science Bulletin, 23: 389-392.

[23] Xie, J., Wu, X., Tang, J.J., Zhang, J.E. and Chen. X. 2010. Chemical fertilizer reduction and soil fertility maintenance in rice-fish co-culture system. Frontiers of Agriculture in China, 4: 422-429. https://doi.org/10.1007/s11703-010-1049-z
[24] Li, K. 1988. Rice-fish culture in China: A review. Aquaculture, 71: 173186. https://doi.org/10.1016/0044-8486(88)90257-8

[25] Halwart, M. and Gupta, M.V. 2004. Culture of fish in rice fields. Food and Agriculture Organization of the United Nations and the WorldFish Center, p. 83.

[26] BRKB. 2010. Rice statistics in Bangladesh. Bangladesh Rice Knowledge Bank (BRKB), Bangladesh Rice Research Institute, Gazipur, Bangladesh.

[27] Parvez, M.S., Sarker, M.S., Azad, M.S. and Salekuzzaman, M. 2006. Effect on water quality, pond productivity and growth of carps in polyculture system by using homestead organic wastage as a pond manure. International Journal of Sustainable Agricultural Technology, 2(2): 45-50.

[28] Dugan, P., Dey, M.M. and Sugunan, V.V. 2006. Fisheries and water productivity in tropical river basins: enhancing food security and livelihoods by managing water for fish. Agricultural Water Management, 80: $262-275$ https://doi.org/10.1016/j.agwat.2005.07.017

[29] Lightfoot, C., van Dam, A. and Costa-Pierce, B.A. 1992. What's happening to rice yields in rice-fish systems? In: dela Cruz, C.R., Lightfoot, C., Costa-Pierce, B.A., Carangal, V.R. and Bimbao, M.P. (Eds.), Rice-Fish Research and Development in Asia. ICLARM Conference Proceedings 24, Manila, Philippines, pp. 177-183.

[30] Parvez, M.S., Salekuzzaman, M., Hossain, M.E. and Azam, K. 2012. Economics and productivity of rice cum freshwater prawn (Macrobrachium rosenbergii) in the gher farming system. International Researchers, 1(3): 39-49.

[31] Rahman, M.A. and Parvez, M.S. 2016. Integrated rice-fish farming in Bangladesh: Prospects, Potentials, Practices and Benefits. In: Rahman, M.A. and Dasic, P. (Eds.), Proceedings of the International Conference on Agricultural, Food, Biological and Health Sciences (AFBHS-16), Eminent Association of Pioneers, Kuala Lumpur, Malaysia, pp. 130-132.

[32] Rahman, M.A., Parvez, M.S. and Marimuthu, K. 2016. Prospects, potentials, practices and benefits of integrated rice-fish farming in Bangladesh. International Journal of Biological, Ecological and Environmental Sciences, 5(1): 46-49.

[33] Ahmed, N., Ahammed, F. and Brakel, M.V. 2008. An economic analysis of freshwater prawn Macrobrachium rosenbergii farming in Mymensingh, Bangladesh. The World Aquaculture Society, 38: 37-50.

[34] Berg, H. 2001. Pesticide use in rice and rice-fish farms in the Mekong Delta, Vietnam. Crop Protection, 20: 897-905. https://doi.org/10.1016/S0261-2194(01)00039-4 